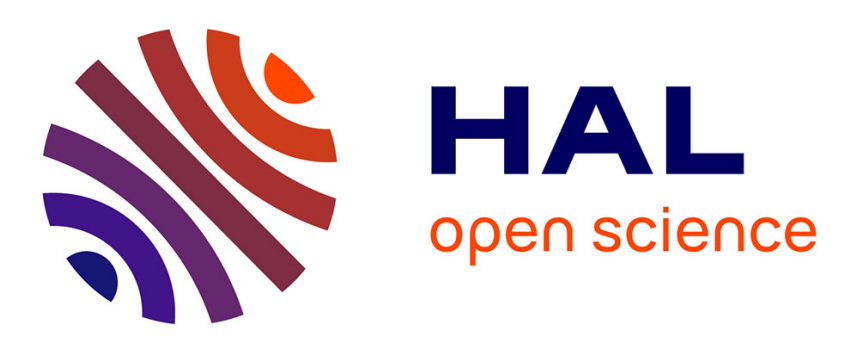

\title{
Chain branching detection by Cole-Cole modeling of rheological properties changes during PET mechanical recycling
}

K.L Nait-Ali, A Bergeret, Laurent Ferry, Xavier Colin

\section{- To cite this version:}

K.L Nait-Ali, A Bergeret, Laurent Ferry, Xavier Colin. Chain branching detection by Cole-Cole modeling of rheological properties changes during PET mechanical recycling. Polymer Testing, 2012, 31, pp.500-504. 10.1016/j.polymertesting.2012.01.006 . hal-01082755

\section{HAL Id: hal-01082755 \\ https://hal.science/hal-01082755}

Submitted on 7 Apr 2015

HAL is a multi-disciplinary open access archive for the deposit and dissemination of scientific research documents, whether they are published or not. The documents may come from teaching and research institutions in France or abroad, or from public or private research centers.
L'archive ouverte pluridisciplinaire HAL, est destinée au dépôt et à la diffusion de documents scientifiques de niveau recherche, publiés ou non, émanant des établissements d'enseignement et de recherche français ou étrangers, des laboratoires publics ou privés. 


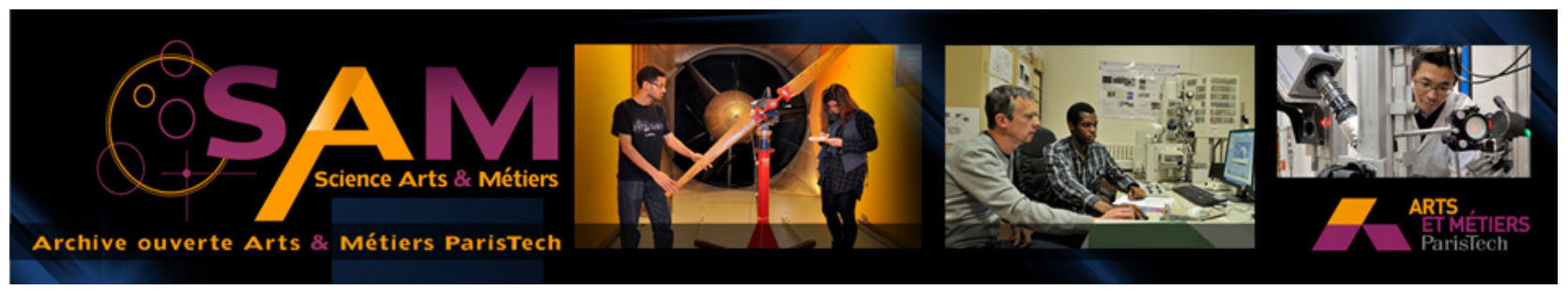

Science Arts \& Métiers (SAM)

is an open access repository that collects the work of Arts et Métiers ParisTech researchers and makes it freely available over the web where possible.

This is an author-deposited version published in: http://sam.ensam.eu

Handle ID: .http://hdl.handle.net/10985/8895

\section{To cite this version :}

K.L. NAIT-ALI, A BERGERET, L FERRY, Xavier COLIN - Chain branching detection by Cole-Cole modeling of rheological properties changes during PET mechanical recycling Polymer Testing - Vol. 31, p.500-504 - 2012 


\title{
Chain branching detection by Cole-Cole modeling of rheological properties changes during PET mechanical recycling
}

\author{
K.L. Nait-Ali ${ }^{\mathrm{a}, *}$, A. Bergeret ${ }^{\mathrm{b}, 1}$, L. Ferry ${ }^{\mathrm{b}, 1}, \mathrm{X}$. Colin ${ }^{\mathrm{c}, 2}$ \\ ${ }^{a}$ Terre Armee Internationale, RED Division, 1 bis rue du Petit Clamart, Bâtiment C, B.P. 135, 78148 Vélizy-Villacoublay, France \\ ${ }^{\mathrm{b}}$ Ecole des Mines d'Alès, Centre CMGD, 6 Avenue de Clavières, 30100 Alès, France \\ ${ }^{\mathrm{c}}$ ARTS ET METIERS ParisTech PIMM (UMR CNRS 8006), 151 Boulevard de l'Hôpital, 75013 Paris, France
}

Keywords:

Poly(ethylene terephthalate)

Recycling

Chain branching

Crosslinking

Cole-Cole model

\begin{abstract}
A B S T R A C T
The detection of branched chains in thermally degraded thermoplastic polymers is far from simple, especially at a low conversion ratio, mainly because of the low sensitivity of commonly used laboratory analytical techniques. The objective of this article is to present an approach able to demonstrate the formation of such macromolecular structures during thermal degradation of molten PET at low oxygen partial pressures (typically for pressures lower than 9\% of atmospheric pressure). Such ageing conditions are met during PET mechanical recycling by extrusion, and can be simply reproduced by sequential nitrogen/ air tests in a rheometer cavity. The approach consists of a careful analysis of the complex shear modulus changes in a Cole-Cole diagram. Values obtained for Cole-Cole model parameter $\mathrm{K}^{\prime}$ indicate clearly an accumulation of branched chains in the melt with the time of residence in the reactor.
\end{abstract}

\section{Introduction}

It is now well recognized that thermal oxidation is the main source of problems during PET mechanical recycling by extrusion. Irreversible macromolecular changes are the result of the competition between chain scission and branching, and eventually crosslinking [1-9]. In a recent literature compilation on the rheological properties changes of molten PET during its mechanical recycling, it has been shown that the relative predominance of both macromolecular changes depends on the extruder geometry [10]. Indeed, a poorly oxygenated geometry (characterized by small feeder and die sections, and a long screw) would lead to the predominance of chain branching $[1,2]$ up to the complete polymer gelation (by crosslinking) [2].

\footnotetext{
* Corresponding author. Tel.: +33146018571.

E-mail addresses: linda.nait-ali@terre-armee.com (K.L. Nait-Ali), anne. bergeret@mines-ales.fr (A. Bergeret), xavier.colin@ensam.eu (X. Colin).

1 Tel.: +33466785344.

2 Tel.: +33144246147.
}

On the contrary, a well oxygenated geometry (characterized by large feeder and die sections, and a short screw) would lead to the predominance of chain scission and an important reduction in molar mass with the number of extrusion cycles [3-9]. Thus, the rheological behavior of molten PET would be highly oxygen partial pressure dependent. The critical oxygen partial pressure, for which chain scission equilibrates with chain branching, has been estimated at around 9\% of the atmospheric pressure [10].

In order to attempt to elucidate such a complex degradation phenomenon, the extruder reactor has been represented, in a first approach, by a relatively simple form in which the molten polymer is confined within the pressurized zone (i.e. middle part of the extruder) and is only in contact with air, at atmospheric pressure, at both extremities (at the feeder and die) of the extruder. Thus, according to this simplified scheme, chain scission and branching would occur successively during an extrusion operation, since each one is largely favored in a distinct zone of the reactor. Such a succession of macromolecular changes has been successfully reproduced in the carefully controlled 
environment (in temperature, oxygenation and shearing) of a rheometer cavity [10]. Indeed, sequential nitrogen/air tests have clearly shown a dramatic decrease in the Newtonian viscosity in ambient air followed by a slowdown, stabilization and, finally, an increase in the Newtonian viscosity when air is substituted by nitrogen in the rheometer cavity.

A general kinetic model has been built for molten PET thermal oxidation to predict these Newtonian viscosity changes [10]. Although satisfactory agreement has been obtained between theory and experiment, the formation of branched chains could be considered as speculative. Unfortunately, common laboratory analytical techniques (e.g. IR spectrometry, solid state ${ }^{13} \mathrm{C} N M R$, etc.) are not sufficiently sensitive to detect the presence of such macromolecular structures, especially at a low conversion ratio of the oxidation process.

Many researches have been conducted on different types of polymers, including polyesters $[11,12]$, polyolefins [13] and or polymer blends [12,14-16], using different rheological methods in the molten state. They generally observe the influence of branched polymers on the complex modulus. Some of these papers show the dependency of storage modulus, loss modulus and phase angle on the polymer molecular structure, generally the polydispersity and branching. These parameters are quite sensitive to the evolution of polymer macromolecules even at low ratio. Two main representations are used: Van GurpPalmen plots [17] and the plots of logarithm of storage modulus vs logarithm of loss modulus proposed by Han and Kim [18].

These models are commonly used to characterize the amount of branched long-chains or the changes in polymer morphology, but it is often difficult to dissociate even qualitatively the effects of polydispersity and branching on the polymer rheological behavior. It is thus necessary to use a complementary method (for instance steric exclusion chromatography (SEC)) to determine independently the polydispersity. As a result, it would be difficult to envisage using such methods for studying PET degradation.

We turned towards an alternative rheological method expected to be considerably more sensitive in order to detect and quantify the presence of branched macromolecules even at a low conversion ratio of the degradation process. It consists of a careful analysis of the changes in the complex modulus of molten PET in a Cole-Cole diagram. Indeed, considering that the relationships, established in previous papers $[19,20]$, between polymer structure and Cole-Cole model parameters remain valid for thermally degraded polymers, it then becomes possible to elucidate the corresponding structural changes from Cole-Cole model parameters changes. The objective of the present article is to check the validity of this approach in the case of PET mechanical recycling by extrusion.

\section{Theory: presentation of the Cole-Cole model}

Several models have been proposed in the literature in order to quantify the molecular mobility in the amorphous phase of semi-crystalline polymers and composite matrices. Among them, the biparabolic model developed by Perez et al. [20,21] gives an expression of the complex shear modulus $\mathrm{G}^{*}$ as a function of several parameters having a physical meaning:

$G^{*}=G^{\prime}+i G^{\prime \prime} G_{C}+\frac{G_{I}-G_{C}}{1+Q\left(i \omega \tau_{m r}\right)^{-K^{\prime}}+\left(i \omega \tau_{m r}\right)^{-K}}$

where $\omega$ is the pulsation, $G_{C}$ and $G_{I}$ are respectively the relaxed and unrelaxed modulus and $\tau_{\mathrm{mr}}$ is the time for molecular relaxation.

Cole-Cole model parameters $\mathrm{K}, \mathrm{K}^{\prime}$ and $\mathrm{Q}$ are obtained by plotting $G^{\prime \prime}$ versus $G^{\prime}$, as illustrated in Fig. 1.

All these parameters are very interesting to study because they are related to polymer structure. The parameter $\mathrm{K}^{\prime}\left(0<\mathrm{K}^{\prime}<1\right)$ corresponds to correlation effects at the defects (structural) level such as entanglements or nodes. Its value decreases when the defect density - i.e. the chemical and/or physical crosslinking density, the filler fraction, the impurity concentration, etc. - increases.

According to Cavaille et al. [22] this parameter governs the height and width of the relaxation peak when plotting $\tan \alpha=\mathrm{f}(\omega)$. It means that $(\tan \alpha)_{\max }$ is higher when $\mathrm{K}^{\prime}$ is close to unity and decreases when $\mathrm{K}^{\prime}$ decreases. As an example, $\mathrm{K}^{\prime}$ will be lower than 0.7 for crosslinked resins (effect of nodes) and will be close to unity for amorphous (or melt) thermoplastic polymers.

The parameter $\mathrm{K}\left(0<\mathrm{K}<\mathrm{K}^{\prime}<1\right)$ corresponds to correlation effects at the monomer scale. It governs the high frequency of the curve as presented in Fig. 1.

The amplitude $\mathrm{Q}$ is related to the defect concentration with a higher amplitude for lower defect concentrations.

\section{Materials \& techniques}

\subsection{Materials}

A post-consumer PET (called RE0) obtained by grinding, washing and milling different French trademarked bottles has been used for this study. This material is characterized by: a crystallinity ratio $\mathrm{X}_{\mathrm{C}} \approx 33 \%$ (heating rate $=10^{\circ} \mathrm{C} / \mathrm{min}$ ), a melting point $\mathrm{T}_{\mathrm{m}} \approx 250{ }^{\circ} \mathrm{C}$, a weight average molar mass $\mathrm{M}_{\mathrm{W}} \approx 63 \mathrm{~kg} \mathrm{~mol}^{-1}$ and an intrinsic viscosity $\mathrm{VI} \approx 0.70 \mathrm{dL} / \mathrm{g}$ (solvent : o-chlorophenol).

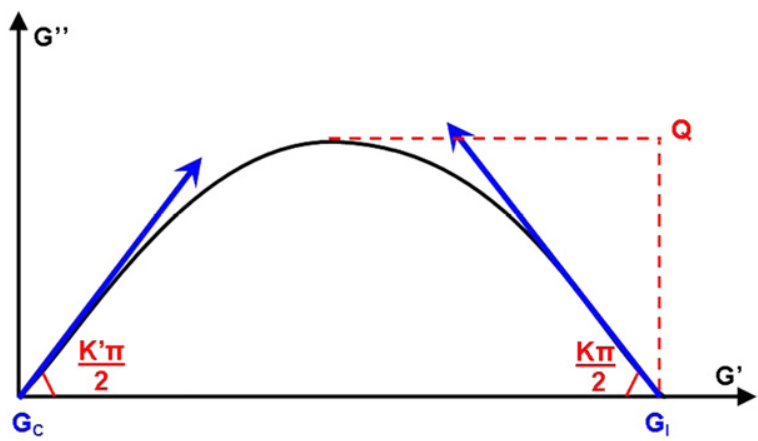

Fig. 1. Graphic determination of parameters $K, K^{\prime}, G_{c}$ and $G_{l}$ from a ColeCole diagram. 


\subsection{Melt processing}

Before any processing operation, as received RE0 flakes were dried $15 \mathrm{~h}$ at $120^{\circ} \mathrm{C}$ in an oven under primary vacuum in order to reduce moisture content down to less than 100 ppm and, therefore, prevent any hydrolytic degradation of molten PET during processing. Then, extrusion was performed with a single screw extruder (Compact type from Fairex) with the following geometry:

- Feeder area: $\mathrm{S}_{0}=3800 \mathrm{~mm}^{2}$;

- Die area: $\mathrm{S}_{\mathrm{L}}=80 \mathrm{~mm}^{2}$;

- Extruder length: $\mathrm{L}=88 \mathrm{~cm}$.

It is a well oxygenated extruder geometry leading to a predominance of chains scission over chain branching [10].

Extrusion was performed at $260{ }^{\circ} \mathrm{C}$ in ambient air with an average speed of $80 \mathrm{rpm}$. The average residence time was approximately $50 \mathrm{~s}$. Successive extrusions were performed in the same conditions. Reprocessed samples will be called REn, $\mathrm{n}$ being the number of extrusion cycles $(0 \leq \mathrm{n} \leq 6)$.

\subsection{Sequential nitrogen/air experiments}

After each extrusion, REn films were dried according to the previous procedure and the dynamic flow properties of the molten polymer were determined at $280^{\circ} \mathrm{C}$ in nitrogen with a Rheometrics ARES rheometer using a coaxial parallel plate geometry (diameter $=50 \mathrm{~mm}$, gap $=1 \mathrm{~mm}$ ). Sweep angular frequency experiments were then performed at an angular frequency interval of $100-0.1 \mathrm{rad} \cdot \mathrm{s}^{-1}$ with a strain amplitude of $20 \%$ (see Fig. 2).

These experiments show that REn behavior is Newtonian in the low frequency range, typically for $\omega \leq 10 \mathrm{rad} \cdot \mathrm{s}^{-1}$. For this reason, sequential nitrogen/air experiments were performed with an angular frequency of $10 \mathrm{rad} \cdot \mathrm{s}^{-1}$.

During these experiments, the molten polymer was first exposed at $280^{\circ} \mathrm{C}$ in nitrogen until the Newtonian viscosity reached an asymptotic value. At this time, the atmosphere was switched to ambient air over a period of two minutes.

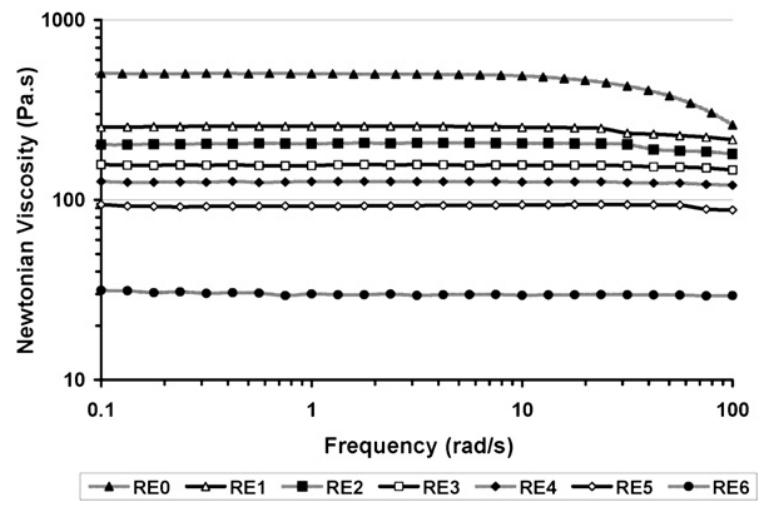

Fig. 2. Evolution of Newtonian viscosity with frequency for recycled PET at $280{ }^{\circ} \mathrm{C}$.
This atmospheric sequence was repeated three times in order to reproduce and accumulate the irreversible structural changes occurring in the extruder, from the feeder to the die, as described in a previous article [10].

\section{Results \& discussion}

\subsection{Analysis of macromolecular changes in the rheometer cavity}

Results of sequential nitrogen/air experiments on REn samples are reported in Fig. 3.

All curves present the same general shape. RE1 changes versus atmospheric conditions and exposure time has been detailed in a previous article [10].

- In the first stage, the slight decrease in Newtonian viscosity has been attributed to the thermal degradation of structural irregularities.

- The second stage may correspond to a dramatic decrease in molar mass due to the fact that chain scission predominates largely over chain branching or crosslinking.

- Then, (third stage) the substitution of ambient air by nitrogen in the rheometer cavity leads to a sudden and fast slowdown of the Newtonian viscosity until a critical value of $9 \%$ of oxygen [10], at which chain branching equilibrates with chain scission. Below this critical value, chain branching predominates over chain scission and viscosity increased again until all oxygen is consumed by the chemical reaction in the rheometer cavity.

The differences between all these curves concern the initial Newtonian viscosity and amplitude of Newtonian viscosity changes.

Fig. 4 presents the relative variation of viscosity with the number of extrusion cycles at the second and third stages (viscosity compared to the first stage). It is clearly demonstrated on this graph that, for the third stage, the relative viscosity increases with the number of extrusion cycles, especially for the sixth extrusion. This could be due

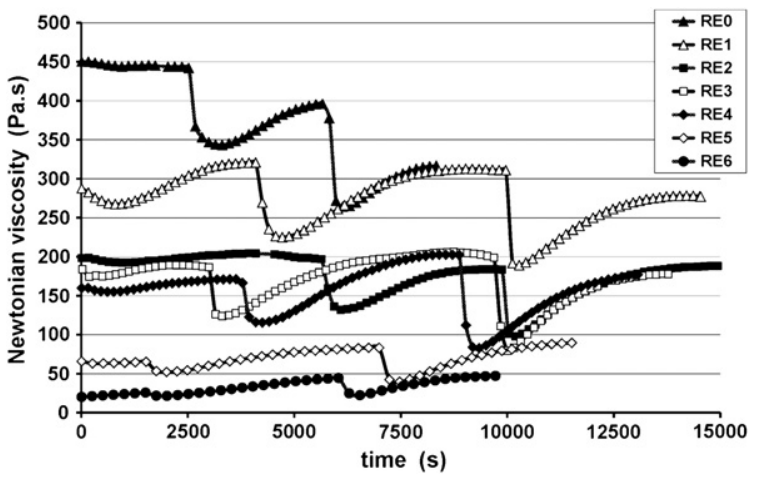

Fig. 3. Changes in Newtonian viscosity of recycled PET at $280{ }^{\circ} \mathrm{C}$ during sequential nitrogen/air experiments. 


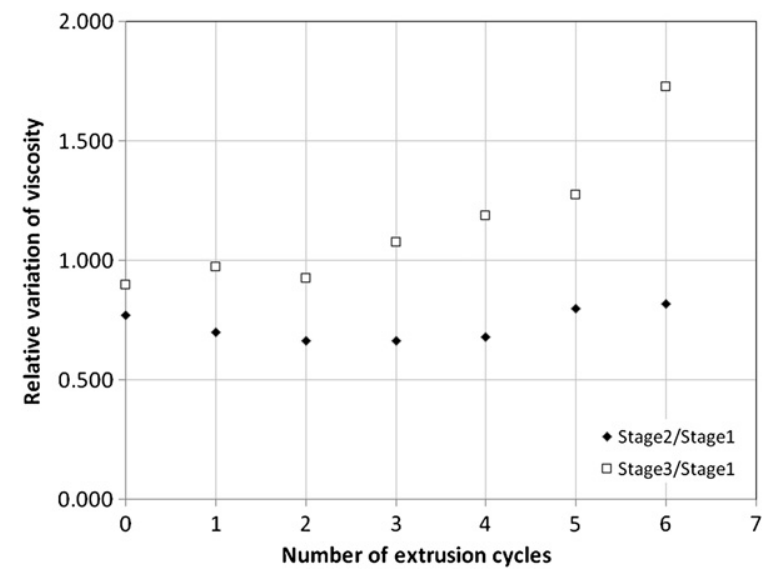

Fig. 4. Relative variation of recycled PET viscosity versus number of extrusion cycles.

to the high amount of short molecular chains which contribute highly to the polymer branching under nitrogen atmosphere. Concerning the evolution of relative viscosity at the second stage, the more degraded sample shows the lowest loss of viscosity, probably because of the average chain lengths: chain-cleavage leads statistically to a more important loss of relative viscosity if the initial average molecular weight is high. Thus, the impact of oxidation on REn samples would depend also on initial conversion ratio. The higher the amount of low molecular chains, the higher is the relative increase of viscosity by branching.

In conclusion, these curves confirm the high influence of oxygen partial pressure and initial conversion ratio on REn rheological behaviour.

\subsection{Influence of the PET recycling steps on Cole-Cole model parameters}

In the molten state, it is not possible to plot the entire Cole-Cole diagram because the frequency range under study is restricted to $100-0.1 \mathrm{rad} \cdot \mathrm{s}^{-1}$. Nevertheless, it remains possible to evaluate parameter $\mathrm{K}^{\prime}$, which is a very interesting quantity because it is related to the molecular mobility and structural changes occurring during the extrusion cycles, or their simulation by sequential nitrogen/ air experiments in a rheometer cavity.

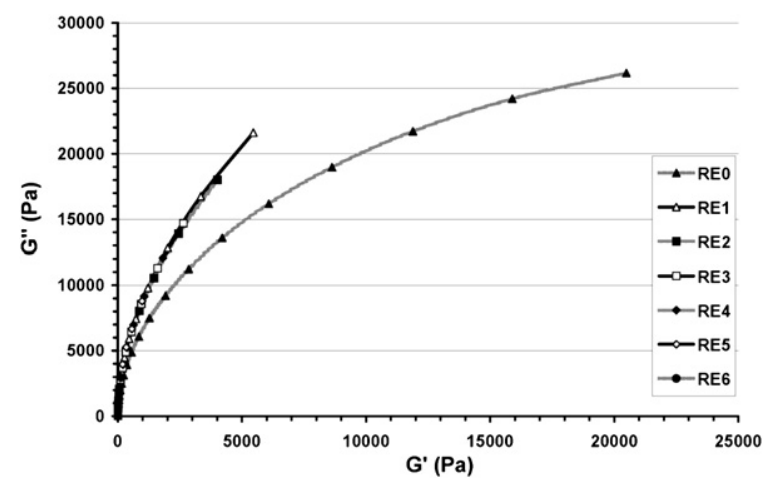

Fig. 5. Cole-Cole diagram for recycled PET during the first stage.

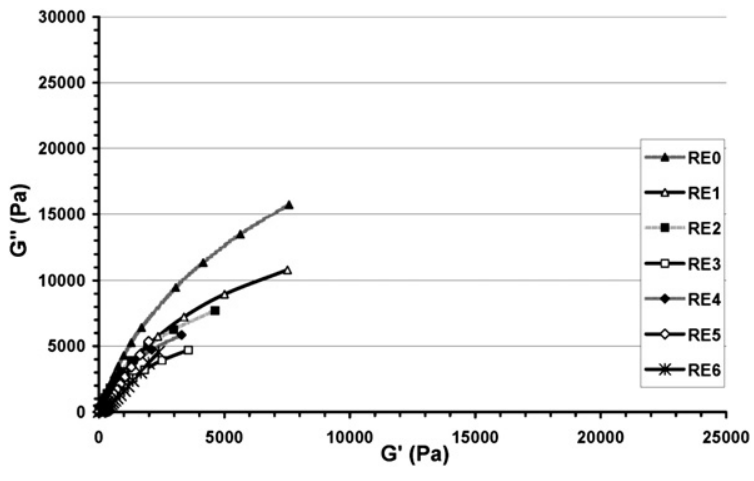

Fig. 6. Cole-Cole diagram for recycled PET during the third stage.

Table 1

$\mathrm{K}^{\prime}$ versus number of extrusion cycles during the first and third stages.

\begin{tabular}{lll}
\hline PET samples & $\mathrm{K}^{\prime} 1$ st stage & $\mathrm{K}^{\prime}$ 3rd stage \\
\hline RE0 & 0.99 & 0.79 \\
RE1 & 0.99 & 0.78 \\
RE2 & 0.99 & 0.75 \\
RE3 & 0.99 & 0.75 \\
RE4 & 0.99 & 0.69 \\
RE5 & 0.99 & 0.75 \\
RE6 & 0.99 & 0.74 \\
\hline
\end{tabular}

The changes in parameter $\mathrm{K}^{\prime}$ with the number of extrusion cycles (RE0 to RE6) and the number of nitrogen/ air sequences in the rheometer cavity (especially first and third stages of the nitrogen/air sequences described before) are presented in Figs. 5 and 6 respectively.

$\mathrm{K}^{\prime}$ values for the first and third stages are reported in Table 1:

Results suggest that structural changes induced by the extrusion cycles and nitrogen/air sequences are not identical. Indeed it can be observed that the parameter $\mathrm{K}^{\prime}$ remains constant during the first stage, confirming that chain scission is largely predominant over chain branching during the extrusion cycles. On the contrary, in the third stage, the parameter $K^{\prime}$ is a decreasing function of the number of extrusion cycles, confirming an accumulation of branched chains in the molten PET during the sequential nitrogen/air experiment. This may indicate that the influence of branching on the molecular mobility is greater when chain length is short. In our case, $\mathrm{K}^{\prime}$ values remain located in the [0.6-0.8] interval which corresponds to the rheological behavior of a branched polymer [22].

The decrease of amplitude Q (see Figs. 5 and 6) in the Cole-Cole diagrams is generally attributed to a decrease in average molecular weight. In this case, it confirms degradation of the molten polymer in air (second stage of sequential test described in part 4.1).

\section{Conclusions}

The Cole-Cole model seems to be an interesting tool to detect the presence of branched chains in molten polymers at a low conversion ratio, a domain that is, in general, 
inaccessible for commonly used analytical laboratory techniques. A carefully carried out analysis of the complex shear modulus during PET mechanical recycling by extrusion, and sequential nitrogen/air tests in a rheometer cavity has given access to two totally different variations of a specific parameter designated as $\mathrm{K}^{\prime}$ measured from the Cole-Cole slope at high temperature-low frequency. This parameter gives evidence of the relative predominance of chain scission and branching. When chain scission predominates largely over chain branching, $\mathrm{K}^{\prime}$ remains constant, with a value close to unity. On the contrary, when chain branching is no longer negligible, $\mathrm{K}^{\prime}$ is a decreasing function of time of residence in the reactor, with values located in the [0.6-0.8] interval.

It will be very useful to examine the validity of this approach on virgin polymers containing different concentrations of well-known branched macromolecular structures. Such polymers could be readily synthesised.

\section{References}

[1] K.L. Nait-Ali, X. Colin, A. Bergeret, L. Ferry, P. Ienny, Rheologica modelisation of PET degradation during its recycling by extrusion, in: Proceedings 23rd Annual Meeting Polymer Processing Society (cd-rom) (2007), p. 8

[2] R. Assadi, X. Colin, J. Verdu, Irreversible structural changes during PET recycling by extrusion, Polymer 45 (13) (2004) 4403-4412.

[3] W. Romao, M.F. Franco, Y.E. Corilo, M.N. Eberlin, M.A.S. Spinacé, A De Paoli M-, Poly(ethylene terephthalate) thermo-mechanical and thermo-oxidative degradation mechanisms, Polym. Degrad. Stab. 94 (10) (2009) 1849-1859

[4] F.P. La Mantia, M. Vinci, Recycling poly(ethylene terephthalate), Polym. Degrad. Stab. 45 (1994) 121-125

[5] M. Paci, F.P. La Mantia, Competition between degradation and chain extension during processing of reclaimed poly(ethylene terephthalate), Polym. Degrad. Stab. 61 (1998) 417-420.

[6] M. Frounchi, Studies on degradation of PET mechanical recycling, Macromol. Symp. 144 (1999) 465-469.
[7] M.A.S. Spinacé, M.A. De Paoli, Characterization of poly(ethylene terephthalate) after multiple processing cycles, J. Appl. Polym. Sci. 80 (2001) 20-25.

[8] J.D. Badia, F. Vilaplana, S. Karlsson, A. Ribes-Greus, Thermal analysis as a quality tool for assessing the influence of thermo-mechanica degradation on recycled poly(ethylene terephthalate), Polym. Test. 28 (2009) 169-175.

[9] A. Oromiehie, A. Mamizadeh, Recycling PET beverage bottles and improving properties, Polym. Int. 53 (2004) 728-732.

[10] L.K. Nait-Ali, X. Colin, A. Bergeret, L. Ferry, Kinetic analysis and modelling of PET macromolecular changes during its mechanical recycling by extrusion, Polym. Degrad. Stab. 96 (2011) 236-246.

[11] C. Liu, P. Chen, J. He, Q. Fan, Influence of long-chain branching on linear viscoelastic flow properties and dielectric relaxation of polycarbonates, Polymer 45 (2004) 2803-2812.

[12] S. Hashemi, Work of fracture of PBT/PC blend: effect of specimen size, geometry, and rate of testing, Polym. Eng. Sci. 37 (1997) 912 921.

[13] P.M. Wood-Adams, J.M. Dealy, A.W. DeGroot, O.D. Redwine, Effect of molecular structure on the linear viscoelastic behavior of polyethylene, Macromolecules 33 (2000) 7489-7499.

[14] L. Mascia, A. Valenza, Reactive dual-component compatibilizers for polycarbonate/high-density polyethylene blends, Adv. Polym. Technol. 14 (1995) 327-335.

[15] R. Greco, A. Sorrentino, Polycarbonate/ABS blends: a literature review, Adv. Polym. Technol. 13 (1994) 249-258.

[16] H. Ohishi, T. Ikehara, T. Nishi, Phase morphology of polystyrenepolyarylate block copolymer/polycarbonate blends and their application to disk substrates, J. Appl. Polym. Sci. 82 (2001) 2566-2582.

[17] M. Van Gurp, J. Palmen, Time-temperature superposition for polymeric blends, Rheol Bull. 67 (1998) 5-8.

[18] C.D. Han, J.K. Kim, On the use of time-temperature superposition in multicomponent/multiphase polymer systems, Polymer 34 (1993) 2533-2539.

[19] A. Bergeret, A. Agbossou, N. Alberola, P. Cassagnau, T. Sarraf, Micromechanical properties of random copolymers of styrene with methacrylic acid. Experimental and theoretical approaches, Eur. Polym. J. 28 (10) (1992) 1201-1218.

[20] N. Alberola, A. Bergeret, Physical modeling of the interphase in amorphous thermoplastic/glass beads composites, Polym. Comp. 15 (6) (1994) 442-452.

[21] J.Y. Cavaille, J. Perez, P. Johari, Molecular theory for the rheology of glasses and polymers, Phys. Rev. B39 (4) (1989) 2411-2422.

[22] J. Perez, J.Y. Cavaille, S. Etienne, C. Jourdan, Physique revue, Phys. Appl. 23 (1988) 125-135. 